\title{
Proyecto de Cooperación entre el IAPH y el CENCREM de La Habana
}

La Consejería de Cultura articula su política de cooperación a través de la Viceconsejería que, desde finales de 2000, ha reactivado su actividad en este campo dando coherencia a toda la cooperación cultural, diseñando para ello dos proyectos globales de cooperación, uno con Marruecos y otro con Cuba.

El proyecto global de Cuba se articula en tres líneas de cooperación:

I. El Libro y la Edición, que tiene como organismo responsable en Cuba al Instituto Cubano del Libro.

2. La Cinematografía, actualmente en proceso de definición, que tiene como contraparte al Instituto Cubano de las Artes e Industrias Cinematográficas.

3. Y el Patrimonio Histórico, en el cual interviene la Dirección General de Bienes Culturales, a través del Instituto Andaluz del Patrimonio Histórico (IAPH), y cuyo organismo responsable en Cuba es el Centro Nacional de Conservación, Restauración y Museología de la Habana (CENCREM).

En esta última línea se enmarca el proyecto de cooperación Formación, asistencia técnica y material al Centro Nacional de Conservación, Restauración y Museología de la Habana (CENCREM), que se ha desarrollado durante el 200I. En él han participado la Viceconsejería de Cultura como organismo responsable del seguimiento técnico, la Empresa Pública de Gestión de Programas Culturales como organismo ejecutor y el Instituto Andaluz del Patrimonio Histórico, como entidad encargada de la coordinación gestión del proyecto, a través del Centro de Documentación y el Departamento de Formación. Para su ejecución se ha contado con los fondos de cooperación para el desarrollo de la Consejería de Presidencia, a través de la Dirección General de Asuntos Europeos y Cooperación Exterior.

El proyecto se ha desarrollado durante los meses de Marzo a Junio de 2001. Aunque los primeros planteamientos son del999, no es hasta principios de 2001 cuando, tras el estudio de puntos en común y necesidades de ambas instituciones, se concretan sus objetivos:
- Intercambiar y adaptar experiencias metodológicas y prácticas en el campo de la Documentación e Información para su implantación en el CENCREM e IAPH.

- Dotar de equipamiento informático al CENCREM para el desarrollo de actuaciones relacionadas con la Documentación e Información.

- Realizar cursos de formación en el IAPH y en el CENCREM con objeto de difundir las experiencias en el campo de la Conservación y de la Documentación e Información del Patrimonio Histórico.

- Proponer líneas futuras de cooperación entre las dos instituciones en el campo de la Conservación, Documentación e Información del Patrimonio Histórico.

De acuerdo con estos objetivos durante 200 I se han realizado las siguientes actuaciones:

a) Transferencia de conocimientos en el área de Información y Documentación del Patrimonio Histórico.

EI CENCREM estaba poniendo en marcha varias iniciativas relacionadas con el desarrollo de bases de datos del Patrimonio Histórico, que coincidían con distintos trabajos del Centro de Documentación del IAPH. En este sentido se puso a disposición del CENCREM la experiencia que el Centro de Documentación ha desarrollado sobre la base de datos de bienes muebles, las actuaciones realizadas en el Centro de Intervención sobre la organización de la documentación y la propuesta de un registro informatizado de los procesos para las intervenciones de Bienes Muebles, así como la aplicación informática de Información Gráfica que permite el tratamiento de distintas tipologías documentales.

Esta transmisión de conocimientos se realizó a través de un programa de estancias en el IAPH, que desarrollaron dos técnicos del CENCREM con objeto de conocer los trabajos desarrollados por el IAPH en general y del Centro de Documentación en particular, fundamentalmente sobre los temas ya comentados. El contenido de este trabajo se estructuró en una serie de fases, a corto y largo plazo que se concretarían a lo largo de
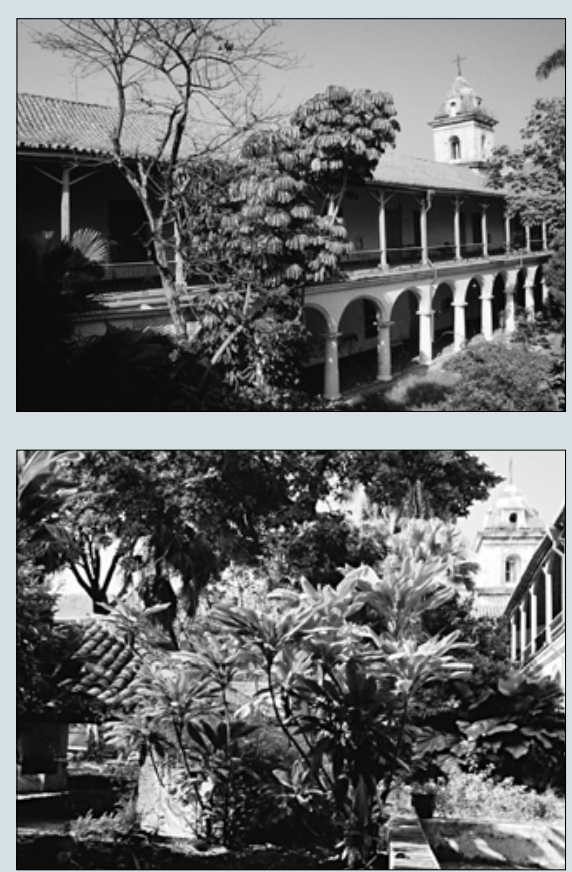

un calendario establecido, con el seguimiento y asesoramiento del IAPH.

Las estancias permitían por un lado conocer las distintas actividades que realiza el Centro de Documentación del IAPH y trabajar de forma conjunta con sus técnicos para la puesta en marcha del proyecto.

b) Dotación de equipamiento informático para implementar el desarrollo e implantación de bases de datos de Patrimonio Histórico.

Como resultado del análisis de necesidades realizado con los técnicos del CENCREM se propuso la dotación a los distintos departamentos de equipamiento informático y material fungible necesario para poder llevar a cabo actuaciones en el ámbito de la Documentación e Información del Patrimonio Histórico.

c) Curso de formación sobre el "Sistema de Información del Patrimonio Histórico de Andalucía" (Sede: CENCREM)

La experiencia del Centro de Documentación del IAPH en el campo de la Documentación e Información podía interesar también 
a otros organismos cubanos relacionados con el Patrimonio Cultural. Por esta razón se propuso la celebración de un curso sobre el Sistema de Información del Patrimonio Histórico de Andalucía, impartido por técnicos del IAPH y que estaría dirigido a técnicos del CENCREM y de otras instituciones cubanas relacionadas con el Patrimonio Histórico.

d) Curso de formación especializada sobre "la Rehabilitación y Restauración de Edificios Históricos en Cuba" (Sede: IAPH)

EI CENCREM posee una larga trayectoria formativa en temas de rehabilitación y restauración de Bienes Inmuebles, que transfieren su larga experiencia en este ámbito. Por otro lado, el IAPH tiene previsto potenciar la intervención en el Patrimonio Inmueble. El resultado de la suma de intereses fue la organización de un curso sobre conservación de edificios históricos en Cuba, impartido por un técnico del CENCREM en la sede del IAPH.

La valoración de las actuaciones ha sido muy positiva, ya que han permitido un intercambio de conocimientos e información, han favorecido el contacto interdisciplinar entre profesionales y el descubrimiento mutuo de instituciones con objetivos y contenidos tan similares como son el IAPH y el CENCREM, permitiendo aunar esfuerzos para la consecución común de unos mismos fines: la tutela del Patrimonio Cultural.

El trabajo conjunto llevado a cabo durante las estancias ha enriquecido a los técnicos del IAPH aportándoles nuevas visiones y ha servido de excusa para la revisión y evaluación del trabajo realizado. A su vez a los técnicos del CENCREM les ha supuesto el punto de arranque de una serie de proyectos a implantar en el Centro. El desarrollo del trabajo ha sido muy satisfactorio, aunque algunos de los objetivos planteados no han llegado a cumplirse por completo debido fundamentalmente a la complejidad de las actuaciones emprendidas. Por esta razón se considera necesario continuar con las actuaciones iniciadas hasta su culminación.

Los cursos han tenido un objetivo general: la difusión y la información del Patrimonio Histórico en las facetas ya citadas, que ha sido cumplido con creces gracias a la cualificación del profesorado y al nivel profesional de los alumnos. Los objetivos específicos, como el intercambio de especialistas, el conocimiento de otras experiencias similares y el estableci-

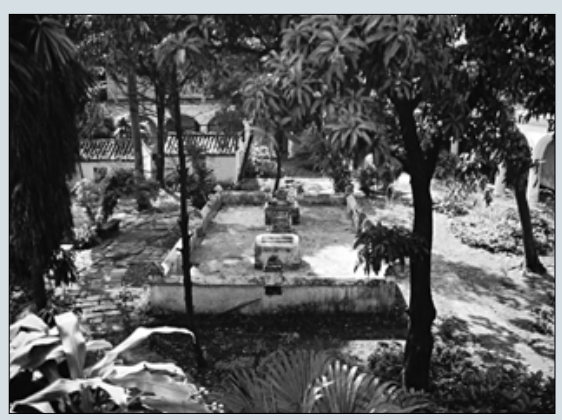

miento de contactos institucionales han sido también alcanzados, valorándose tanto por parte de los alumnos como de los profesores como una experiencia enriquecedora.

El Curso sobre el "Sistema de Información del Patrimonio Histórico de Andalucía" tenía dos objetivos fundamentales: transferir, en primer lugar, experiencias y metodologías tanto al CENCREM como a otras Instituciones relacionadas con el Patrimonio, y, en segundo lugar detectar posibles líneas de cooperación que pudieran beneficiar también a otros organismos e instituciones relacionadas con el Patrimonio Histórico. Los objetivos se han cumplido, el curso ha servido para contactar con distintas instituciones cubanas que están desarrollando proyectos relacionadas con las materias objeto del curso y que están muy interesadas en el asesoramiento del Centro de Documentación en el desarrollo de bases de datos del Patrimonio Histórico.

Sería deseable la continuidad del proyecto de cooperación sobre la base de la culminación de las acciones emprendidas y la puesta en marcha de otras líneas que consoliden la cooperación entre ambas instituciones y posibiliten la incorporación de otras instituciones cubanas relacionadas con el Patrimonio Histórico. La propuesta de líneas de cooperación para el futuro se concreta en los siguientes puntos:

I. Intercambio y adaptación de experiencias metodológicas y prácticas en el campo de la Documentación e Información de interés para el CENCREM y el IAPH.

2. Dotación de equipamiento al CENCREM como apoyo para el desarrollo de actuaciones relacionadas con la Documentación e Información y Conservación del Patrimonio Histórico.

3. Formación en Patrimonio Histórico, con objeto de difundir las experiencias en el campo de la Conservación y de la Docu-

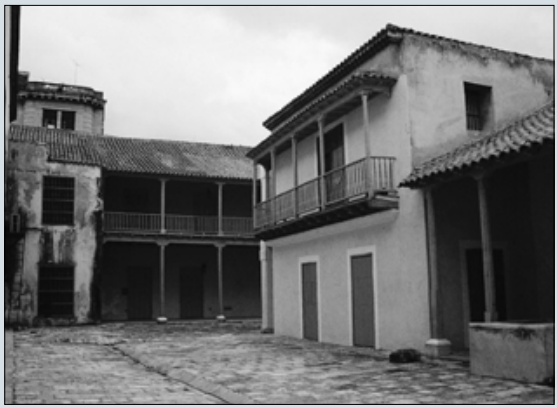

mentación e Información del Patrimonio Histórico, a través de cursos (presenciales o a distancia a través de Internet), becas y estancias.

4. Asesoramiento en temas de Documentación e Información, incorporando a otras instituciones cubanas relacionadas con el Patrimonio Histórico.

5. Difusión del Patrimonio Histórico que podría incluir asesoramiento en técnicas de presentación del Patrimonio y turismo cultural.

6. Crear junto con el CENCREM un sitio Web, que podría ampliarse a otras instituciones de Patrimonio Histórico iberoaméricanas como punto de referencia e intercambio de información y experiencias vía internet. Este proyecto incluiría la elaboración de un boletín digital, especializado en Patrimonio Histórico.

En resumen, se han abierto canales para la comunicación y el trabajo conjunto, elaborándose nuevas propuestas de colaboración para el futuro. En este caso la cooperación es entendida como intercambio y diálogo entre profesionales, entre aquellos que comparten una cultura común, un idioma común y una misma preocupación por su Patrimonio Histórico.

Isabel Luque Ceballos

Departamento de Formación del IAPH

Valle Muñoz Cruz

Centro de Documentación del IAPH 